\title{
Effect of the own colony odor on olfactory and thermal preferences of the honeybee (Apis mellifera) workers
}

\author{
Przemysław Grodzicki ${ }^{1}$, Michał CaputA ${ }^{1}$, Bartosz Piechowicz ${ }^{2}$ \\ ${ }^{1}$ Department of Animal Physiology, Faculty of Biology and Environmental Protection, N. Copernicus University, \\ Lwowska 1, 87-100, Torun, Poland \\ ${ }^{2}$ Department of Ecotoxicology, Institute of Biotechnology, University of Rzeszow, Werynia 502, 36-100, Kolbuszowa, \\ Poland
}

Received 4 October 2016 - Revised 27 July 2017 - Accepted 24 August 2017

\begin{abstract}
Honeybee foragers were tested on their preference for the own colony odor either separately, in an olfactometer, or in combination with their temperature preference, in thermal gradient chambers, where their motor activity was also recorded. The bees in the gradient chambers were either deprived of their colony odor for 9 days or exposed to the odor during the experimental days 4-9. The source of odor was wax from the own colony. Bees were attracted by the odor, and this attraction culminated at night. Thermal preference and motor activity fluctuated in a circadian rhythm both in absence and in combination with the own colony odor but there was an upward drift of both variables in bees deprived of the odor. The data are discussed on the background of detrimental effects of isolation from the own colony odor possibly indicating an age related phenomenon.
\end{abstract}

social insects / colony odor / thermal behavior / locomotor activity / isolation stress

\section{INTRODUCTION}

Honeybees (Apis mellifera) are able to sense a great number of different olfactory stimuli (Reinhard and Srinivasan 2009, Richard and Hunt 2013, Bortolotti and Costa 2014). The stimuli play a crucial role both in physiological responses of single individuals, and in the honeybee colony behavior. Various odorants, produced by the colony and sensed by individual honeybee workers, can be involved, among others, in the communication between members of the colony (Bortolotti and Costa 2014). This way, all the honeybee colony members and castes can modify each other's behavior. One of the most important kinds of odor sensed by honeybees is the odor of their nest. Its primary and vital function is to

Corresponding author: P. Grodzicki, grodzick@umk.pl Manuscript editor: Bernd Grünewald determine the identity of the colony members (Nunez et al. 2008). This odor is a mixture of volatiles originating from the compounds building up the nest wax, such as fatty acids and carbohydrates, together with the pheromones released by the brood, honeybee workers and the queen, and also the substances originating from food material.

Honeybees are permanently exposed to their own colony odor and sensing this odor allows guarding bees to distinguish between nest mates and foreign bees as well as intruders of other species. This recognition system, acquired by the worker honeybees after their emergence, and functioning during the imago lifetime, is highly adaptive and may be compared to the vertebrate immune system (D'Ettore et al. 2006). The first aim of the present investigation was to estimate the attractiveness for worker honeybees of their own colony odor.

Olfactory learning and memory, and consequently, the ability of honeybees to distinguish 
their own odors from those of foreign origin might influence many physiological and behavioral systems of single bees, composing the superorganism of the honeybee colony. Among others, it is likely that the own colony odor affects the insects' thermoregulatory system. Currently, to the best of our knowledge, there is a lack of information concerning the effect of different odors on honeybee workers' thermal behavior. Furthermore, honeybees show aggressive-defensive behavior associated with social thermoregulation (Stabentheiner et al. 2002, 2007). Hence, the second aim of the present study was to examine whether the own colony odor changes the worker honeybees' thermal preferences. We expected that the own colony odor may reverse the circadian rhythmicity of ambient temperature selected in a thermal gradient by single (isolated) bees to the pattern typical of small groups of bees (Grodzicki and Caputa 2005). The third aim of the investigation was to examine the effect of the odor on longterm trends of thermal behavior, possibly reflecting aging processes in worker honeybees. We expected that the bees deprived of their own colony odor for more than a week may show some signs of aging.

\section{MATERIAL AND METHODS}

\subsection{Animals}

Altogether, 188 worker honeybees (Apis mellifera carnica) were used throughout the study. Because the aim of the investigation was to check circadian rhythmicity and aging only the oldest bees, performing their tasks outside the hive (guards and foragers), which exhibit the rhythm of locomotor activity (Moore 2001), were collected. In experiments concerning the own colony odor preference, a cohort of 130 worker honeybees was collected from a single hive of an apiary located near Torun in Central Poland. The insects walking around the hive entrance were caught few times during a period between June and July 2014. Another cohort of 58 worker honeybees was collected within a period of June to August 2015 from another hive of the same apiary. The both cohorts were obtained from large, strong colonies counting about 40-45 thousand individuals each, which were reared in wooden boxes.

\subsection{Olfactometric estimation of the own colony odor preference}

The olfactory preference was tested on single bees $(n=20)$ and on small groups consisting of five bees $(n=22)$. The tests were performed using a six-arm stellar olfactometer OLF0001 (producer: Andrzej Zienkiewicz Zakład RemontowoMontażowy Aparatury Laboratoryjnej, Torun, Poland) (Figure 1). Compressed air, which was blown throughout each arm of the olfactometer, was the odor carrier in three channels of the device. Thus, bees had a chance to choose between three channels with the odor of their own colony or remaining three without it. These channels were arranged alternately. The whole system was covered with a sheet of glass.

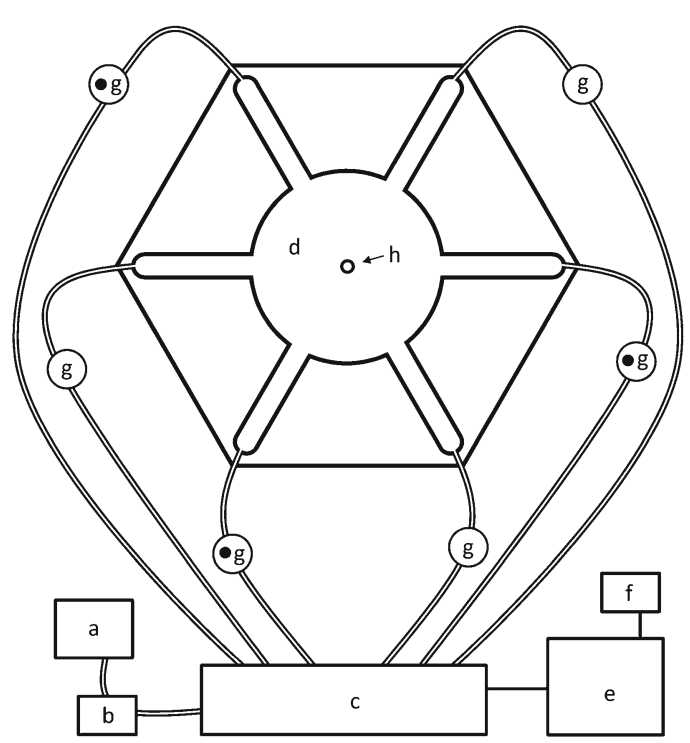

Figure 1. Experimental setup for estimation of olfactory preferences of single bees or groups of five bees. a a container with compressed air, $\mathbf{b}$ a set of carbon filters, c eight channel flow meter G245, d central arena, where the insects were placed, and six arms, into whose distal parts, the air was blown, e working station with the software "Olfak" to operate the rotameter and "BioVid" for visual registration, $\mathbf{f}$ a setup for visual registration, $\mathbf{g}$ glass flasks containing pure air (no extra symbol) or the own colony odor samples. $(\bullet), \mathbf{h}$ the outflow of air. 
A computer running under Windows 7 and BioVid ${ }^{\mathrm{TM}}$ (Ferro Software, Poland) software was used for video capturing. The device was illuminated using a white light fluorescent lamp (PHILIPS MASTER TL-D 18W/840) of 220 lx brightness until $1800 \mathrm{~h}$, and then red led lamps of $1.5 \mathrm{~lx}$ were used. Bees were placed on the olfactometer's arena at $0800 \mathrm{~h}$, and the test was started after a 6-h period of their adaptation to the experimental conditions, and was continued until $0600 \mathrm{~h}$ of the next day. The experiments were conducted at a constant ambient temperature of $25 \pm 2{ }^{\circ} \mathrm{C}$. Each arm of the olfactometer was equipped, at its middle part, with a small container filled with $50 \%$ sucrose syrup.

As a source for colony odor pieces of $10 \times 10 \times 5 \mathrm{~mm}$ fresh honeycomb wax were used (with no traces of honey), recently produced in the same hive, which was used to collect the experimental bees. The samples were taken from a cover of the box in the least invasive manner.

The device was cleaned after each experiment by a water-soluble detergent and then three times washed with acetone pure for analysis (Chempur, Poland) and again three times with ether petroleum (Chempur, Poland, with a purity of HPLC), and finally once with distilled water. After each experiment, all gas tubes (bev-a-line 4, USA) and flasks of the delivery system were replaced.

Bees were placed in the central arena and they had an opportunity to enter the arms of the olfactometer. Each of them was tested for $16 \mathrm{~h}$ (from 1400 to $0600 \mathrm{~h}$ ) and their position in the arms with or without the odor was recorded by inspecting the photographs, which were taken every $10 \mathrm{~min}$. The choice of the odor channels was given a value of +1 while entering the channels without the odor was given a value of -1 , both in the experiments on single bees and in those on groups of the insects. Throughout the experiment, each bee could easily return to the arena and choose another arm of the apparatus.

\subsection{Thermal preference experiments}

The thermal gradient system for recording selected ambient temperature was described in details previously (Grodzicki and Caputa 2005, 2012, 2014). The system consisted of a series of four $1 \mathrm{~m} \times 0.08 \mathrm{~m} \times 0.035 \mathrm{~m}$ computer-controlled aluminum chambers. One end of each chamber was cooled by a cryostat while the opposite end was simultaneously heated by a thermostat, which generated a linear gradient of temperatures ranging from 7 to $50^{\circ} \mathrm{C}$. The temperature distribution in each chamber was recorded by a series of 16 thermocouples placed at equal distances along its floor. The temperature data were processed and recorded by the computer (Operating system OS: Windows XP) by means of Grad-K.exe software (producer: Andrzej Zienkiewicz Zakład Remontowo-Montażowy Aparatury Laboratoryjnej, Toruń, Poland-no numbered versions), which was a part of the equipment. The position and movements of each bee were recorded in infrared radiation by a video camera (Sony Handycam HDR-SR5E), and simultaneously the data, at $10 \mathrm{~s}$ sequences, were digitized by the computer in video files using Pinacle Studio ver.11.0.0.5082 (Pinacle Systems Inc.). The single individuals were placed into the gradient chambers immediately after their collection. During the experiment, honeybees had unrestricted access to food (honey) and water, which were placed in 16 pairs of small containers distributed at equal distances along the chambers. Each chamber was covered with a transparent plexiglas lid, which allowed illuminating it according to a fixed photoperiod, and did not interfere with watching the honeybees.

Four experimental series were carried out: (i) nine days exposure to thermal gradient conditions without odor stimuli $(n=20)$, (ii) exposure to the own colony odor placed in the middle part of the chambers at a temperature of $18^{\circ} \mathrm{C}(n=15)$, (iii) exposure to the odor placed at $9{ }^{\circ} \mathrm{C}(n=7)$, and (iv) exposure to the odor distributed over the full length of the chambers $(n=16)$. The odor was applied into the chambers always at noon of the fourth day since starting the experiment, which was continued for the next 5 days. The odor sources were fresh beeswax pieces $10 \times 10 \times 5 \mathrm{~mm}$ collected as described in the previous section. In the experimental series, (iv) the pieces were fragmented.

Because according to our previous observations (Grodzicki and Caputa 2005, 2012, 2014), isolated worker honeybees in thermal 
gradient selected higher temperatures (i.e., 28$32{ }^{\circ} \mathrm{C}$ ) than those at which the odor source was placed in the first two series of our experiments; these sites were chosen intentionally in order to create a conflict between the thermal preferences and a desire for an attractive smell of the home hive. The exception to this rule was the experimental series, (iv) in which the colony odor was distributed over the full length of the gradient chamber. In both control and experimental series, LD 12:12 photoperiod was used (lights off 1800-0600 h). Actually, at night, red led lamps of $1.5 \mathrm{~lx}$ brightness were used while the daylight was obtained from white light bulbs of $51 \mathrm{~lx}$.

\subsection{Estimation of locomotor activity}

Locomotor activity of worker honeybees in the gradient chamber was analyzed using the abovementioned video recordings of their thermal behavior. During the visual inspection of the consecutive 10-s video recordings, each insect was given a value of 1 when it was active (walking, running, rotating, or changing its posture) or 0 when it was motionless. The results of the inspection were averaged over 6 -h periods $(0600$ $1200 \mathrm{~h} ; 1200-1800 \mathrm{~h} ; 1800-2400 \mathrm{~h}$ and 0000 $0600 \mathrm{~h}$ ).

\subsection{Data analysis}

Olfactory preferences were presented as 2-h averages \pm SE. The overall impact of time of day on the own colony odor preference was determined using one-way ANOVA. The statistical significance of differences between the results obtained under each of the applied experimental conditions was determined using Tukey HSD test. Differences were considered statistically significant when $P<0.05$.

The overall impact of time of day (6-h averages $\pm \mathrm{SE}$ ), the effect of the colony odor, and the effect of the odor location on selected ambient temperature and locomotor activity were determined using one-way ANOVA. Additionally, the combined effect of the abovementioned factors, i.e., the effect of the colony odor location on selected ambient temperature and locomotor activity during night and day or the effect of the odor location on selected ambient temperature and locomotor activity was determined using two-way ANOVA. The statistical significance of differences between the results obtained under each of the applied experimental conditions was determined using Tukey HSD test for unequal N (Spjotvoll/Stoline test). The selected temperature and locomotor activity values obtained under control conditions were compared with those affected by the abovementioned three variants of the colony odor location.

\section{RESULTS}

\subsection{A preference for the own colony odor}

Time courses of the preference are shown in Figure 2. Both individually tested, single worker honeybees and groups of five individuals exhibited a distinct preference for their own colony odor. The overall $16-\mathrm{h}$ average of the preference index achieved a value of $+0.22 \pm 0.02$ for single bees and a value of $+0.86 \pm 0.05$ for the groups of bees. In single bees, 2-h averages of the preference index changed depending on time period of the preference recording $(F(8,1931)=3.41$; $P<0.0007)$. The preference index reached the maximum 2 -h value of $+0.41 \pm 0.20$ within a period of $0200-0400 \mathrm{~h}$ (Figure 2a). It was significantly higher than those recorded in the following time periods: $1400-1600 \mathrm{~h}$ $(P<0.05), 1600-1800$ h $(P<0.05), 1800-$ $2000 \mathrm{~h}(P<0.05)$, and $0400-0600 \mathrm{~h}$ $(P<0.05)$. Two-hour averages of the preference index for the groups also varied depending on time period of the preference recording $(F(8,2125)=10.63 ; P<0.001)$. The index reached its maximum of $+1.54 \pm 0.16$ within a period of 2000-2200 h (Figure 2b). It was significantly higher than those recorded at $1400-1600 \mathrm{~h}(P<0.001), 1600-1800 \mathrm{~h}$ $(P<0.001), 1800-2000$ h $(P<0.05), 0200-$ $0400 \mathrm{~h}(P<0.001)$, and $0400-0600 \mathrm{~h}$ $(P<0.05)$. In the abovementioned periods of the preference culmination, $71 \%$ of the single bees and $65.4 \%$ of the groups' members were attracted by their own colony odor. 


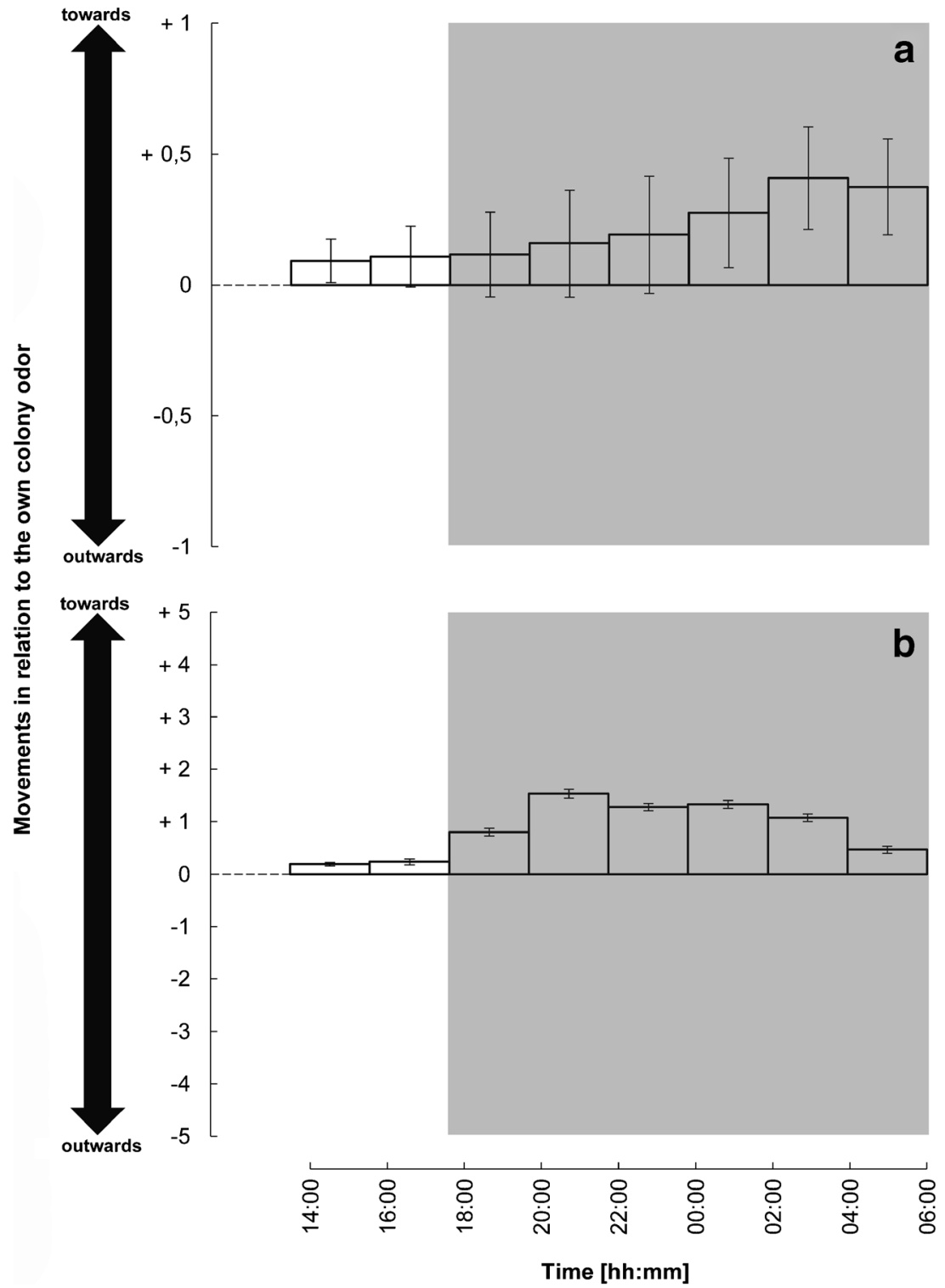

Figure 2. Two-hour averages of the olfactory preference index (where the choice of the channels containing the own colony odor was given a value of +1 while entering the channels without the odor was given a value of -1 , both in experiments on single bees and in those on groups of the insects) for single worker honeybees (a) and the groups containing five bees (b). Gray area shows darkness period.

3.2. Effects of the own colony odor on thermal preference and on locomotor activity of worker honeybees

Averaging thermal preference and locomotor activity over longer periods of time did not reveal any effect of colony odor. Therefore, we decided to present, in Figure 3, the pooled curves showing time resolved changes in both variables. Both control and the odor-exposed bees exhibited daily oscillations of their temperature preference and locomotor activity. One-way ANOVA showed 


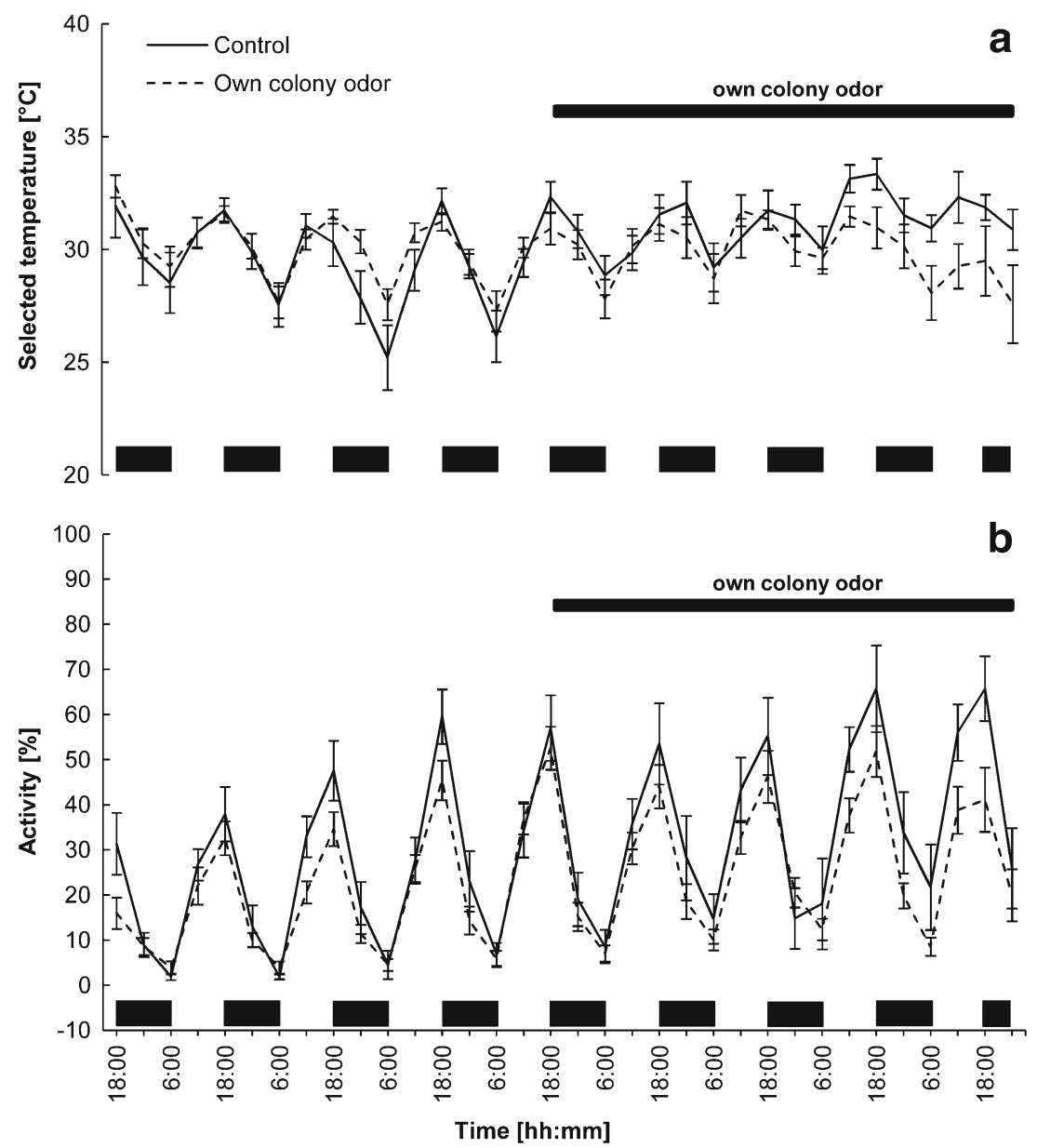

Figure 3. Long-term time courses of 6-h averages \pm SE showing daily changes in selected ambient temperature (a) and locomotor activity (b) in worker honeybees deprived of their colony odor (the control series; $n=20$ ) and in those exposed to the odor (pooled data of three series of the odor application; $n=38$ ). Black bars at the bottom indicate periods of darkness. The long black bar indicates duration of the odor exposure.

that there was a significant ( $\mathrm{R}$ Rao $(2,1542)=5.60 ; P<0.0038)$ effect of the own colony odor on both variables. Furthermore, the post hoc analysis indicated that there was a significant $(P<0.001)$ effect of duration of the exposure to thermal gradient conditions in the control insects, which manifested itself in progressively increasing selected ambient temperature and locomotor activity. The effect was absent in bees exposed to the odor. Two-way ANOVA, concerning the mode of the odor application and the phase of the experiment (initial days 1-4 versus final days 5-9) as main factors indicated that the phase of the experiment ( $R$ Rao
$(2,1536)=25.36 ; P<0.001)$, and the odor application mode $(\mathrm{R}$ Rao $(6,3072)=8.45 ; P<0.001)$ had significant effects on both the selected ambient temperature and locomotor activity of bees. There was also an interaction between these two factors $(\mathrm{R}$ Rao $(6,3072)=4.60 ; P<0.001)$.

A more detailed comparison of daily fluctuations in both the abovementioned variables in control bees deprived of the own colony odor with those in bees exposed to the odor is presented in Figures 4 and 5. Due to the drift of both variables in the control bees we decided to compare the data within days 5-9, i.e., within the period of the odor application. Both under the control and 


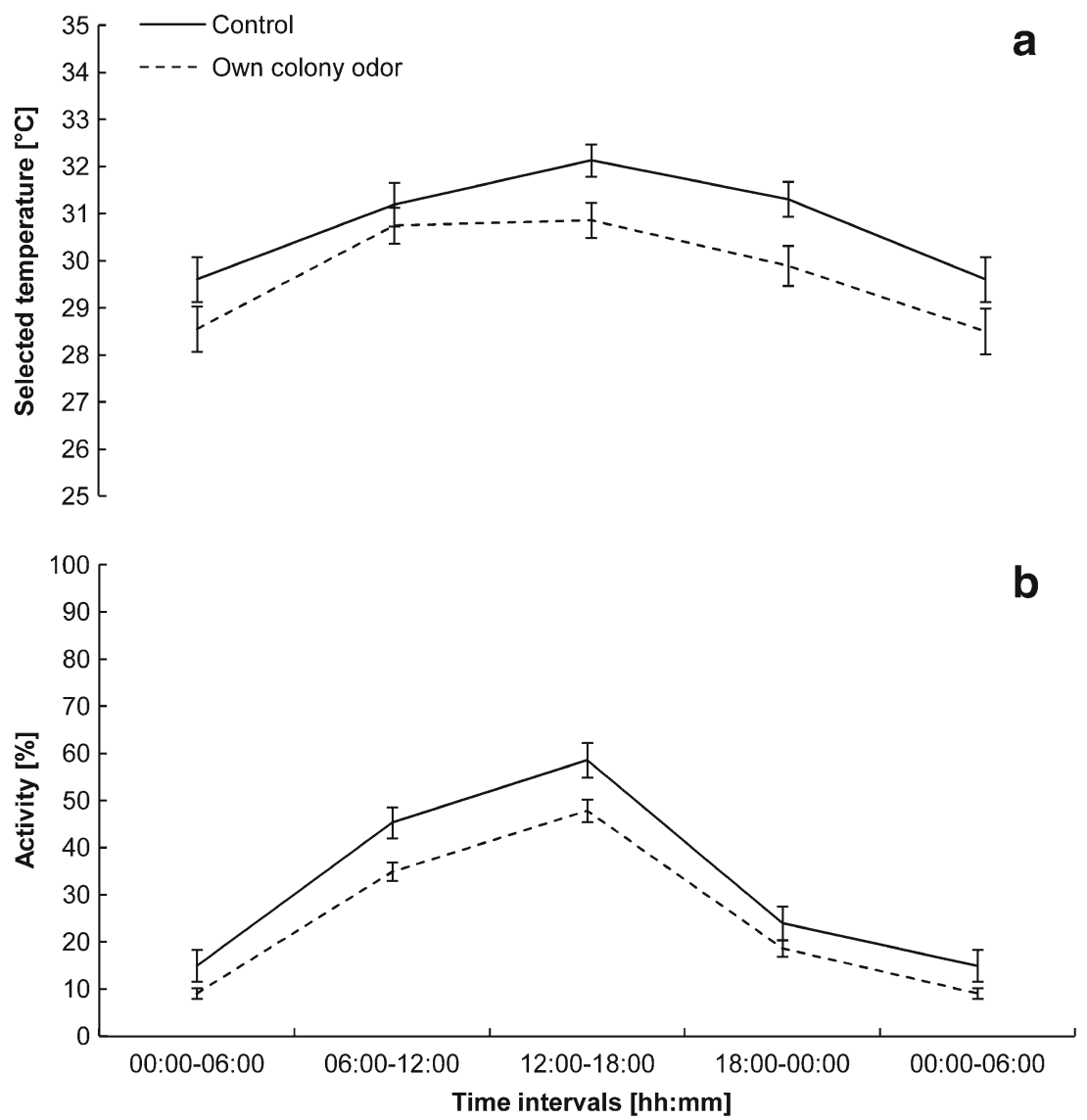

Figure 4. Six-hour averages \pm SE of daily shifts in selected ambient temperature (a) and locomotor activity (b) concerning experimental days 5-9 in bees deprived of their own colony odor (the control series; $n=20$ ) and in those exposed to the odor (pooled data of three series of the odor application; $n=38$ ).

experimental conditions diurnal rhythm of selected ambient temperature (Figures $4 \mathrm{a}$ and $5 \mathrm{a}$ ) and locomotor activity (Figures $4 \mathrm{~b}$ and $5 \mathrm{~b}$ ), culminating in the early afternoon and reaching its lowest values after midnight, was maintained. Surprisingly, bees exposed to the odor placed at the cold end of the gradient chamber, at a temperature of $9{ }^{\circ} \mathrm{C}$, selected their daily highest and lowest temperatures at the beginning of the light (0600$1200 \mathrm{~h})$ and dark (1800-0000 h) phases, respectively (Figure 5a). In this group, exceptionally, the diurnal rhythm of thermal preference was not synchronized with that of locomotor activity (Figure 5b).

The effect of exposure to the own colony odor in all experimental series and that of the odor application mode was analyzed using two-way ANOVA. There was a distinct effect of the odor $(\mathrm{R}$ Rao $(2,1123)=17.25 ; P<0.001)$ and its application mode $(\mathrm{R}$ Rao $(4,2246)=3.20$; $P<0.0124)$ on thermal behavior and motor activity of bees and there was an interaction between both factors $(\mathrm{R}$ Rao $(4,2246)=3.20 ; P<0.0124)$.

\section{DISCUSSION}

Social cues such as pheromones emitted by the queen, brood and other worker bees play an important role in the physiology and behavior of worker bees (Hepburn 1998, Moritz and Southwick 1992, Robinson and Huang 1998, Vander Meer and Morel 1998, Wainston and 


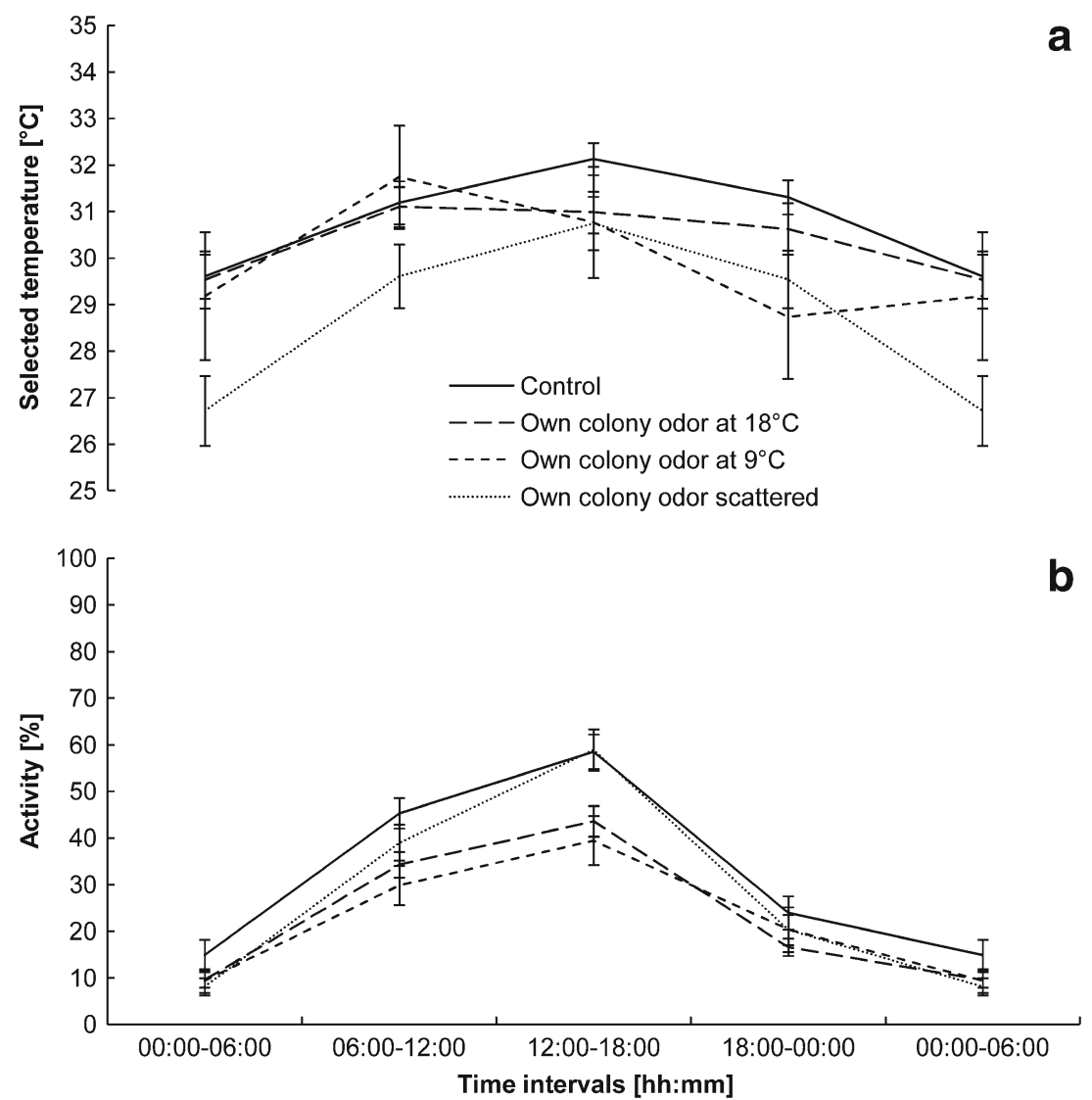

Figure 5. Six-hour averages \pm SE of daily shifts in selected ambient temperature (a) and locomotor activity (b) concerning experimental days 5-9 in bees deprived of their own colony odor (the control series; $n=20$ ) and in those exposed to the odor, which was put in a middle part of the thermal gradient chamber at a temperature of $18{ }^{\circ} \mathrm{C}$ $(n=15)$, at the cold end of the chamber at a temperature of $9{ }^{\circ} \mathrm{C}(n=7)$, or scattered over the full length of the chamber $(n=16)$.

Sblessor 1998, Wilson 1971, 1985). All of them share an effect of their own colony odor, which is likely to be absorbed by the beeswax. This is why we used pieces of the wax as a source of the own colony odor.

Our olfactometric experiments, performed at the start of this investigation, proved that worker honeybees were clearly attracted by their own colony odor. It must be stressed that in our preliminary tests we have been able to show that the wax collected from a foreign hive acts as a distinct repellent. In the present investigation, bees tended to enhance their preference for their own colony odor at night hours, which might be associated with the natural circadian rhythm of their night rest in the hive. The exposures to the odor lasting less than $24 \mathrm{~h}$, however, were too short to prove the existence of such a rhythm. Therefore, in the future experiments we will focus on this question.

In experiments performed in the thermal gradient chambers, both control and the odor-exposed bees exhibited clear daily oscillations of their temperature preference and locomotor activity. In our previous papers (Grodzicki and Caputa 2005, 2014), we have shown that single, isolated worker honeybees selected their highest daily temperatures during the day and the lowest ones at night. On the other hand, groups of the bees tended to reverse this rhythm. Moreover, we were able to prove that the rhythm was endogenous 
(Grodzicki and Caputa 2012). In the present paper, we hypothesized that the own colony odor could modify the pattern of thermal behavior of the isolated bees. We expected them to change the pattern to that typical for groups of bees. That actually was not the case. The pattern remained the same but the rhythms of both selected ambient temperatures and locomotor activity of bees exposed to the odor oscillated around lower values than those recorded in control bees. The main cause of the difference was an upward drift of the rhythms in control bees during a 9-day recording period. Such a long period of the insects' separation from their own colony odor seems to be harmful to them. Therefore, the drift might be as regarded as a disturbance possibly associated with accelerated aging processes due to the stressful isolation. In this context, halting the drift in the own colony odor-exposed bees could be regarded as a sign of the reduced isolation stress and an improvement of their well-being.

There are some data on behavioral symptoms of aging in bees. Generally, honeybees are regarded as good and interesting objects of aging processes analysis. Experiments on honeybees' aging have been performed by Remolina et al. (2007) and Rueppel et al. (2007).

The former focused on the effect of bees' age on their coping with ambient stressors, such as starvation, temperature, and oxidative stress. The sensitivity to heat and oxidative stress appears to be less age-dependent than the susceptibility to starvation stress. The decrease in physiological efficiency of bees concerns especially workers being active mainly outside the hive, compared to nurses performing all their tasks within the nest. Symptoms of the senescence and increasing mortality rate were recorded not earlier than at an age between 10 and 30 days after the bees' emergence and reached their limits at an age of 50 days. Conversely, Rueppel et al. (2007) have shown a significant increase in mortality rate with chronological age, but no evidence of an age-dependent decline in locomotion, learning and sucrose responsiveness was found, a topic particularly important for our discussion. This is compatible with social evolution of honeybees, which reinforces maintaining their mobility, sensitivity to light and sucrose responsiveness, i.e., factors influencing the functioning of workers as foragers, as long as possible. The social role, but not the chronological age affects an accumulation of molecular damages to the brain. To optimize the honeybee colony efficiency social evolution and division of labor an intrinsic mortality rate may be decoupled from functional decline. Aging in bees seems to be due to a down-regulation and gradual depletion of internal resources or costly physiological systems such as the immune system, the latter being reflected by a decrease in number of hemocytic cells in aging bees (Amdam et al. 2004, 2005). There are good reasons to believe that worker foragers age more rapidly than other workers, such as nurses, performing all their tasks inside the hive (Omholt and Amdam 2004). According to Neukirch (1982), progression of aging in worker bees is driven by intense flights. Foraging is considered to be associated with a high rate of mechanical senescence (Cartar 1992), frequent exposure to pathogens, and ultraviolet light (Kefuss and Nye 1970). Life expectancy is reduced by wing wear (Neukirch 1982), which leads to increased work load and, as a consequence, to a higher metabolic rate. Forager bees spend the majority of their life outside the protected nest and making over ten trips a day, sometimes at distances up to $2 \mathrm{~km}$, and they are exposed to a high risk of predation, thermal stress, and physical exhaustion, resulting in accumulation of injuries and increased mortality (Remolina et al. 2007). A drop in performance is due to exhaustion of glycogen stores in the flight muscles (Neukirch 1982). In this context, the senescence means reduced ability to rebuilt the stores.

An important question is what was the aging stage of the bees used in our study. We used the workers starting their outside-hive activity, which happens just at their age of 19-21 days. Therefore, they must have already been showing some signs of aging.

One of the most serious challenges for honeybees seems to be their coping with isolation from 
the colony. To the best of our knowledge there are no reports concerning the effect of the isolation on aging of bees. Surely, they need physical contacts with the family members and with chemical stimuli from them to keep proper functions of their nervous system and to survive. The social stimulation is necessary to keep precise nestmate recognition in adult ants Camponotus fellah isolated of the colony (Boulay and Lenoir 2001). The experimental isolation caused a decrease in the intraspecies allocolonial aggression while interspecies aggression remained constant. A decrease in allocolonial aggression could probably be due to a decrease in general aggressiveness of the isolated individuals, which is stimulated in worker-worker interactions through pheromonal and physical communications. The social deprivation might also reduce the insects' ability to recognize their nestmates and to distinguish them from aliens. If so, a question arises whether such an olfactory deprivation could affect also other sensory modalities, for instance mechano- or thermoreception. Unfortunately, there are no data concerning this topic.

Placing the home beeswax in the gradient chamber in its region being hostile to bees, i.e., at a temperature of $9{ }^{\circ} \mathrm{C}$, was clearly a conflict situation between two motivations: the abovementioned distinct preference for the own colony odor and thermal preference of the insects. For an unknown reason, the conflict resulted in a desynchronization of the daily rhythm of selected ambient temperatures in this group of bees in comparison with that recorded in control bees or in those exposed to the odor scattered over the full length of the gradient chamber. In this particular group, the highest daily temperature was recorded at the beginning of the light phase instead of reaching the maximum value in the early afternoon (see Figure 5a). Extremely difficult to explain is also desynchronization of the rhythm of selected ambient temperature in the abovementioned group in comparison with that of locomotor activity in the same group, which, in turn, exactly paralleled the oscillations in the remaining groups (see Figure 5b).

In our future experiments concerning effects of the isolation stress on aging of worker bees, we would like to test the impact of social pheromones, such as the alarm pheromone and queen's odor, as well as effects of various diets on thermal behavior, motor activity, muscle glycogen content, and life-span of the insects.

\section{ACKNOWLEDGEMENTS}

The authors are greatly indebted to Dr. Katarzyna Piątkowska for the preparation of figures and to Ms. Izabela Woźniak, Ms. Patrycja Sigłowa, and Mr. Kazimierz Czepiela for their technical assistance in the experiments.

Contributions P. Grodzicki and M. Caputa conceived this research; PG \& B. Piechowicz performed experiments $\&$ analysis; PG \& MC wrote the paper \& MC revised it.

\section{OPEN ACCESS}

This article is distributed under the terms of the Creative Commons Attribution 4.0 International License (http://creativecommons.org/licenses/by/4.0/), which permits unrestricted use, distribution, and reproduction in any medium, provided you give appropriate credit to the original author(s) and the source, provide a link to the Creative Commons license, and indicate if changes were made.

Effet de l'odeur propre à la colonie sur les préférences olfactives et thermiques des ouvrières de l'abeille Apis mellifera

insectes sociaux / odeur de la colonie / comportement thermique / activité locomotrice / stress lié à l'isolement

Effekte des eigenen Stockgeruchs auf olfaktorische und thermische Präferenzen von Honigbienenarbeiterinnen (Apis mellifera)

Soziale Insekten / Stockgeruch / thermisches Verhalten / lokomotorische Aktivität / Isolationsstress

\section{REFERENCES}

Amdam, G. V., Simões, Z. L. P., Hagen, A., Norberg, K., Schrǿder, K., Mikkelsen, O., Kirkwood, T. B. L., Omholt, S. W. (2004) Hormonal control of the yolk precursor vitellogenin regulates immune function and longevity in honeybees. Exp. Gerontol. 39, 767-773

Amdam, G. V., Aase, A. L. T. O., Seehuus, S. C., Fondrk, M. K., Norberg, K., Hartfelder, K. (2005) Social reversal of immunosenescence in honey bee workers. Exp. Gerontol. 40, 939-947 
Bortolotti, L., Costa, C. (2014) Chemical communication in the honey bee society, in: Mucignat-Caretta C. (Ed.), Neurobiology of Chemical Communication. CRC Press, Boca Raton (FL), pp. 147-210

Boulay, R., Lenoir, A. (2001) Social isolation of mature workers affects nestmate recognition in the ant Camponotus fellah. Behav. Processes 55, 67-73

Cartar, R. V. (1992) Morphological senescence and longevity: an experiment relating wing wear and life span in foraging wild bumble bees. J. Anim. Ecol. 61(1), 225231

D'Ettore, P., Wenseleers, T., Dawson, J., Hutchinson, S., Boswell, T., Ratnieks, F. L. W. (2006) Wax combs mediate nestmate recognition by guard honeybees. Anim. Behav. 71, 773-779

Grodzicki, P., Caputa, M. (2005) Social versus individual behaviour: a comparative approach to thermal behaviour of honeybee (Apis mellifera L.) and the American cockroach (Periplaneta americana L.). J. Insect Physiol. 51, 315-322

Grodzicki, P., Caputa, M. (2012) Photoperiod influences endogenous rhythm of ambient temperature selection by the honeybee Apis mellifera. J. Therm. Biol. 37, 587-594

Grodzicki, P., Caputa M. (2014) Diurnal and seasonal changes in thermal preference of single, isolated bees and small groups of bees (Apis mellifera L.). J. Insect Behav. 27, 701-711

Hepburn, H. R. (1998) Reciprocal interactions between honeybees and combs in the integration of some colony functions in Apis mellifera L. Apidologie 29 , 47-66

Kefuss, J. A., Nye, W. P. (1970) The influence of photoperiod on the flight activity of honeybees. J. Apic. Res. 9, 133-139

Moore, D. (2001) Honey bee circadian clocks: behavioral control from individual workers to wholecolony rhythms. J. Insect Physiol. 47, 843-857

Moritz, R. F. A., Southwick, E. E. (1992) Communication Network of the Superorganism, in: Moritz R. F. A. and Southwick E. E. (Eds.), Bees as Superorganisms. (C) Springer-Verlag, Berlin Heidelberg New York, 110-151

Neukirch, A. (1982) Dependence of the life span of the honeybee (Apis mellifica) upon flight performance and energy consumption. J. Comp. Physiol. 146, 35-40
Nunez, T. M., Nascimento, F. S., Turatti, I. C., Lopes, N. P., Zucchi, R. (2008) Nestmate recognition in a stingless bee: does the similarity of chemical cues determine guard acceptance? Anim. Behav. 75 : 1165-1171

Omholt, S. W., Amdam, G. V. (2004) Epigenetic regulation of aging in honeybee workers. Sci. Aging Knowl. Environ. 26, pe28

Reinhard, J., Srinivasan, M. V. (2009) The role of scents in honey bee foraging and recruitment, in: Jarau S., Hrncir M. (Eds.), Food exploitation by Social Insects: An Ecological, Behavioral, and Theoretical Approach. CRC Press, Boca Raton (FL), pp. 165-182

Remolina, S. C., Hafez, D. M., Robinson, G. E., Hughes K. A. (2007) Senescence in the worker honey bee Apis mellifera. J. Insect Physiol. 53, 1027-1033

Richard, F.-J., Hunt, J. H. (2013) Intracolony chemical communication in social insects. Insectes Soc. 60, 275-291

Robinson, G. E., Huang, Z.-Y. (1998) Colony integration in honey bees: genetic, endocrine and social control of division of labor. Apidologie 29, 159-170

Rueppel, O., Christine, S., Mulcrone, C., Groves, L. (2007) Aging without functional senescence in honey bee workers. Curr. Biol. 17(8), R274

Stabentheiner, A., Kovac, H., Schmaranzer, S. (2002) Honeybee nestmate recognition: the thermal behaviour of guards and their examinees. J. Exp. Biol. 205, 2637-2642

Stabentheiner, A., Kovac, H., Schmaranzer, S. (2007) Thermal behaviour of honeybees during aggressive interactions. Ethology 113 (10), 995-1006

Vander Meer, R. K., Morel, L. (1998) Nestmate recognition in ants, in: Vander Meer, R. K., Breed, M. D., Espiele K. E., Winston, M. L. (Eds.), Pheromone communication in social insects. Westview Press, Boulder, pp 79103

Wainston, M. L., Sblessor, K. N. (1998) Honey bee primer pheromones and colony organization: gaps in our knowledge. Apidologie 29, 81-95

Wilson, E. O. (1971) The insect societies. Cambridge, Massachusetts: Harvard

Wilson, E. O. (1985) The sociogenesis of insect colonies. Science (Washington) 228 (4707), 1489-1495 